\title{
Receptor-Targeted Photodynamic Therapy of Glucagon-Like Peptide 1 Receptor-Positive Lesions
}

\author{
Marti Boss, Desiree Bos, Cathelijne Frielink, Gerwin Sandker, Patricia Bronkhorst, Sanne A.M. van Lith, Maarten Brom, \\ Mijke Buitinga, and Martin Gotthardt
}

Department of Radiology and Nuclear Medicine, Radboud University Medical Center, Nijmegen, The Netherlands

Treatment of hyperinsulinemic hypoglycemia is challenging. Surgical treatment of insulinomas and focal lesions in congenital hyperinsulinism is invasive and carries major risks of morbidity. Medication to treat nesidioblastosis and diffuse congenital hyperinsulinism has varying efficacy and causes significant side effects. Here, we describe a novel method for therapy of hyperinsulinemic hyperglycemia, highly selectively killing $\beta$-cells by receptor-targeted photodynamic therapy (rtPDT) with exendin-4-IRDye700DX, targeting the glucagon-like peptide 1 receptor (GLP-1R). Methods: A competitive binding assay was performed using Chinese hamster lung $(\mathrm{CHL})$ cells transfected with the GLP-1R. The efficacy and specificity of rtPDT with exendin-4-IRDye700DX were examined in vitro in cells with different levels of GLP-1R expression. Tracer biodistribution was determined in BALB/c nude mice bearing subcutaneous CHL-GLP-1R xenografts. Induction of cellular damage and the effect on tumor growth were analyzed to determine treatment efficacy. Results: Exendin-4-IRDye700DX has a high affinity for the GLP-1R, with a half-maximal inhibitory concentration of $6.3 \mathrm{nM}$. rtPDT caused significant specific phototoxicity in GLP-1R-positive cells $(2.3 \% \pm 0.8 \%$ and $2.7 \% \pm 0.3 \%$ remaining cell viability in CHLGLP-1R and INS-1 cells, respectively). The tracer accumulates dose-dependently in GLP-1R-positive tumors. In vivo, rtPDT induces cellular damage in tumors, shown by strong expression of cleaved caspase-3, and leads to a prolonged median survival of the mice (36.5 vs. $22.5 \mathrm{~d}$, respectively; $P<0.05$ ). Conclusion: These data show in vitro as well as in vivo evidence of the potency of rtPDT using exendin-4-IRDye700DX. This approach might in the future provide a new, minimally invasive, highly specific treatment method for hyperinsulinemic hypoglycemia.

Key Words: glucagon-like peptide 1 receptor; exendin; photodynamic therapy; hyperinsulinemic hypoglycemia

J Nucl Med 2020; 61:1588-1593

DOI: 10.2967/jnumed.119.238998

Received Oct. 30, 2019; revision accepted Mar. 25, 2020.

For correspondence or reprints contact: Marti Boss, Radboud University Medical Center, Geert Grooteplein-Zuid 10, P.O. Box 9101, 6500 HB, Nijmegen, The Netherlands.

E-mail: marti.boss@radboudumc.nl

Published online May 8, 2020.

Immediate Open Access: Creative Commons Attribution 4.0 International License (CC BY) allows users to share and adapt with attribution, excluding materials credited to previous publications. License: https://creativecommons. org/licenses/by/4.0/. Details: http://jnm.snmjournals.org/site/misc/permission. xhtml.

COPYRIGHT @ 2020 by the Society of Nuclear Medicine and Molecular Imaging.
I nsulin production by pancreatic $\beta$-cells is usually a well-regulated process. However, uncontrolled overproduction of insulin can arise, in most cases as a result of insulin-producing lesions. Such lesions cause major clinical symptoms, and treatment can be challenging. In adults, these lesions manifest in endogenous adult hyperinsulinemic hypoglycemia, most often caused by an insulinoma, which is an insulin-producing neuroendocrine tumor arising from pancreatic $\beta$-cells ( 1 ). In $0.5 \%-5 \%$ of cases, adult hyperinsulinemic hypoglycemia is caused by nesidioblastosis, characterized by proliferation of abnormal $\beta$-cells throughout the pancreas (2). In neonates, the most common cause of persistent hyperinsulinism is congenital hyperinsulinism (CHI) (3). In diffuse $\mathrm{CHI}$ there is diffuse involvement of the pancreatic $\beta$-cells, whereas in focal $\mathrm{CHI}$ the disease is caused by focal adenomatous islet cell hyperplasia (4). Episodic hypoglycemia due to endogenous hyperinsulinism causes neuroglycopenic and autonomic symptoms. Prolonged hypoglycemia may lead to seizures, loss of consciousness, permanent brain damage, or brain death (5).

Insulinomas and focal $\mathrm{CHI}$ can be cured by surgical removal of the lesion $(3,6)$. Enucleation is possible in cases of superficially localized lesions with sufficient distance from the pancreatic duct (2-3 mm). Otherwise, a more extensive surgical procedure such as partial or distal pancreatectomy may be required. Although such procedures can often be performed laparoscopically $(7,8)$, they remain challenging and may carry major risks of morbidity $(9,10)$. The only surgical treatment option for patients with nesidioblastosis and diffuse $\mathrm{CHI}$ not responding to medication is partial pancreatectomy. Even after such an invasive procedure, hypoglycemic episodes often persist, requiring continued treatment with medication and, in certain cases of $\mathrm{CHI}$, total pancreatectomy $(2,4)$.

Because of these challenges, a novel, preferably minimally invasive treatment option for hyperinsulinemic hypoglycemia in adults, as well as in children, is warranted. In this study, we assessed the feasibility of specific ablation of insulin-producing cells with interstitial photodynamic therapy (PDT). PDT is based on inducing cell death by irradiation of a light-sensitive molecule, or photosensitizer). The photosensitizer absorbs photons and is transferred to a higher-energy state. By transfer of energy from the activated photosensitizer to the oxygen in the surrounding tissue, reactive oxygen species are produced, which can cause cellular damage (11). To ensure efficient and specific delivery of the photosensitizer to the target tissue, the photosensitizer is coupled to a tumor-specific targeting moiety (12).

An attractive targeting moiety for receptor-targeted PDT (rtPDT) of insulin-producing cells is exendin-4. This peptide is a stable analog of the hormone glucagon-like peptide 1 (GLP-1). It 
specifically binds to the GLP-1 receptor (GLP-1R), which is expressed on pancreatic $\beta$-cells and at high levels in nearly $100 \%$ of benign insulinomas (13). GLP-1R imaging using ${ }^{111} \mathrm{In}-$ and ${ }^{68} \mathrm{Ga}$-labeled exendin- 4 has been shown to be a successful preoperative imaging technique for insulinomas (14-16) and is also under investigation in CHI (NCT03768518; clinicaltrials.gov).

We have developed an approach for rtPDT of insulin-producing lesions using the peptide exendin-4 coupled to the photosensitizer IRDye700DX (LI-COR Biosciences). We hypothesize that this novel method will allow specific cell killing of GLP-1R-positive cells.

\section{MATERIALS AND METHODS}

\section{Reagents}

Exendin-4-IRDye700DX was supplied by piCHEM. IRDye700DX NHS ester was obtained from LI-COR Biosciences. IRDye700DX absorbs and emits light in the near-infrared (NIR) range and has a higher extinction coefficient $\left(2.1 \times 10^{5} \mathrm{M}^{-1} \mathrm{~cm}^{-1}\right.$ at $\left.689 \mathrm{~nm}\right)$ than non-NIR photosensitizers $(12,17)$. The $\mathrm{N}$ - $\varepsilon$-amino group of lysine at position 40 was site-specifically modified during solid-phase peptide synthesis with a mercaptopropionic acid, releasing an unprotected exendin-4 with a free thiol function after triisopropylsilane cleavage. IRDye700DX was modified with a maleimide, and coupling to exendin-4 was performed using a thiol reactive crosslinking approach. The purity was more than $90 \%$. Stock solutions of exendin-4-IRDye700DX were prepared in phosphate-buffered saline (PBS). The structure and amino acid sequence of the tracer are shown in Supplemental Figure 1 (supplemental materials are available at http://jnm.snmjournals.org). The absorbance and emission spectra of exendin-4-IRDye700DX are shown in Supplemental Figure 2.

\section{Cell Culture}

Chinese hamster lung (CHL) cells stably transfected with the GLP1R (18) were cultured in Dulbecco modified Eagle medium with $4.5 \mathrm{~g} /$ L D-glucose and GlutaMAX (Invitrogen), supplemented with $10 \%$ fetal calf serum, $100 \mathrm{IU} / \mathrm{mL}$ penicillin $\mathrm{G}, 10 \mathrm{mg} / \mathrm{mL}$ streptomycin, $1 \mathrm{mM}$ sodium pyruvate, $0.1 \mathrm{mM}$ nonessential amino acids, and $0.3 \mathrm{mg} / \mathrm{mL}$ G418 geneticin. The rat insulinoma cell line INS-1 was cultured in RPMI 1640 medium, supplemented with $10 \%$ fetal calf serum, $100 \mathrm{IU} / \mathrm{mL}$ penicillin $\mathrm{G}, 10 \mathrm{mg} / \mathrm{mL}$ streptomycin, $2 \mathrm{mmol} / \mathrm{L} \mathrm{L}$-glutamine, $1 \mathrm{mmol} / \mathrm{L}$ pyruvate, $10 \mathrm{mmol} / \mathrm{L}$ 4-(2-hydroxyethyl)-1-piperazineethanesulfonic acid, and $50 \mu \mathrm{mol} / \mathrm{L}$ 2-mercaptoethanol. The human pancreatic tumor cell line PANC-1 was cultured in RPMI 1640 medium supplemented with $10 \%$ fetal calf serum, $100 \mathrm{IU} / \mathrm{mL}$ penicillin $\mathrm{G}, 10 \mathrm{mg} / \mathrm{mL}$ streptomycin, and $2 \mathrm{mmol} / \mathrm{L}$ L-glutamine.

\section{Competitive Binding Assay}

The half-maximal inhibitory concentrations of exendin-4IRDye700DX and unlabeled exendin, as a reference, were determined using CHL-GLP-1R cells as described previously $(19,20)$. One million cells per well were grown overnight in 6-well plates. The cells were washed twice with PBS and incubated for $4 \mathrm{~h}$ on ice with $50,000 \mathrm{cpm}$ of ${ }^{111}$ In-labeled exendin in the presence of increasing concentrations of exendin-4-IRDye700DX (0.1-300 nM). The cells were then washed with PBS, solubilized with $2 \mathrm{~mL}$ of $\mathrm{NaOH}$, and collected, and the cell-associated activity was measured in a $\gamma$-counter (Wizard 2480; PerkinElmer).

\section{In Vitro rtPDT}

CHL-GLP-1R cells, INS-1 cells, and PANC-1 cells were seeded into 24-well plates (Thermo Scientific) (150,000 cells per well) and grown overnight. Medium was replaced by binding buffer (medium with $0.1 \%$ bovine serum albumin [w/v] [BSA]) with exendin-4-
IRDye700DX (300 nM for CHL-GLP-1R cells and $400 \mathrm{nM}$ for INS-1 and PANC-1 cells [concentrations based on optimization experiments]). As a control, cells incubated with binding buffer only were used. Separate wells were incubated with an excess ( $15 \mu \mathrm{M}$ for CHLGLP-1R cells and $20 \mu \mathrm{M}$ for INS- 1 and PANC- 1 cells) of unlabeled exendin-4 together with exendin-4-IRDye700DX. After incubation at $37^{\circ} \mathrm{C}$ (CHL-GLP-1R cells, $4 \mathrm{~h}$; INS-1 and PANC-1 cells, $24 \mathrm{~h}$ ), cells were washed with binding buffer. Subsequently, cells were irradiated with an NIR light-emitting diode (LED) (21) (emission wavelength, 670-710 nm; forward voltage, $2.6 \mathrm{~V}$; power output, $490 \mathrm{~mW}$ ) using 126 individual LED bulbs ensuring homogeneous illumination (21). CHL-GLP-1R cells were irradiated at $90 \mathrm{~J} / \mathrm{cm}^{2}$ (over $6 \mathrm{~min}$ ). INS-1 and PANC-1 cells were irradiated at $150 \mathrm{~J} / \mathrm{cm}^{2}$ (over $10 \mathrm{~min}$ ). Cells incubated with exendin-4-IRDye700DX that were not irradiated were included as a control. All experiments were performed in triplicate.

Four hours after irradiation, during which the cells were kept at $37^{\circ}$ $\mathrm{C}$ and $5 \% \mathrm{CO}_{2}$, the adenosine triphosphate content as a measure of cell viability was determined using a CellTiter-Glo luminescent assay (Promega Benelux) according to the instructions of the manufacturer. Luminescence was measured using a Tecan Infinite M200 PRO plate reader (PerkinElmer). The adenosine triphosphate content as a measure of cell viability was expressed as a percentage, determined by comparing the luminescent signal with the signal from untreated cells, which were considered $100 \%$ viable.

Additionally, a coculture of INS- 1 and PANC- 1 cells was plated in 24-well plates (70,000 and 40,000 cells per well, respectively). Before seeding, INS-1 cells were labeled with the fluorescent dye DiO and PANC-1 cells with DiD dye according to the manufacturer's protocol (Life Technologies, Thermo Fisher Scientific). The cells were grown overnight and then incubated with $400 \mathrm{nM}$ exendin-4-IRDye700DX in binding buffer or binding buffer alone for $24 \mathrm{~h}$ at $37^{\circ} \mathrm{C}$ and $5 \% \mathrm{CO}_{2}$. Subsequently, the cells were irradiated with $150 \mathrm{~J} / \mathrm{cm}^{2}$ of NIR light. After $4 \mathrm{~h}$, the cells were incubated with $1 \mu \mathrm{g} / \mathrm{mL}$ propidium iodide (Thermo Fisher Scientific) in PBS for $15 \mathrm{~min}$ at room temperature. The cells were visualized using an EVOS microscope (Thermo Fisher Scientific).

\section{Animal Tumor Model}

Female BALB/c nude mice (Janvier), 6-8 wk old, were housed in individually ventilated cages ( 6 mice per cage) under nonsterile conditions with ad libitum access to chlorophyll-free animal chow and water. CHL-GLP-1R cells $\left(5 \times 10^{6}\right.$ cells per mouse in $200 \mu \mathrm{L}$ of Dulbecco modified Eagle medium with $4.5 \mathrm{~g} / \mathrm{L}$ D-glucose and GlutaMAX) were injected subcutaneously on the right flank of the mice.

\section{In Vivo Biodistribution}

Female BALB/c nude mice with CHL-GLP-1R xenografts were injected intravenously with exendin-4-IRDye700DX in $200 \mu \mathrm{L}$ of PBS with $0.5 \%$ BSA (5 mice per group; 1,3 , and $10 \mu \mathrm{g}$ of exendin-4IRDye700DX). Four mice were injected with only PBS with $0.5 \%$ BSA. After $4 \mathrm{~h}$, the mice were killed by $\mathrm{CO}_{2}$ asphyxiation, and the tumor and organs were removed and collected in MagNA Lyser tubes (F. Hoffmann-La Roche Ltd.). Radioimmunoprecipitation assay lysis buffer $(500 \mu \mathrm{L} ; 50 \mathrm{mM}$ (hydroxymethyl)aminomethane-hydrochloride, $\mathrm{pH} 7.4$, with $150 \mathrm{mM} \mathrm{NaCl}, 1 \mathrm{mM}$ ethylenediaminetetraacetic acid, $1 \%$ Triton-X-100 (Dow Chemical Co.), and 1\% sodium dodecyl sulfate) was added to each tube. Organs were homogenized using a MagNA Lyser (F. Hoffmann-La Roche Ltd.) with repeated cycles of 6,000 rpm for $25 \mathrm{~s}$ with cooling on ice for $1 \mathrm{~min}$ between cycles. Organ homogenates of the control mice (injected only with PBS with $0.5 \%$ BSA) were used to create standard curves for exendin-4-IRDye700DX for each organ. A $100-\mu \mathrm{L}$ volume of homogenates was transferred in triplicate to a black flat-bottom 96-well plate, and fluorescence intensity was measured using a Tecan Infinite M200 PRO plate reader 


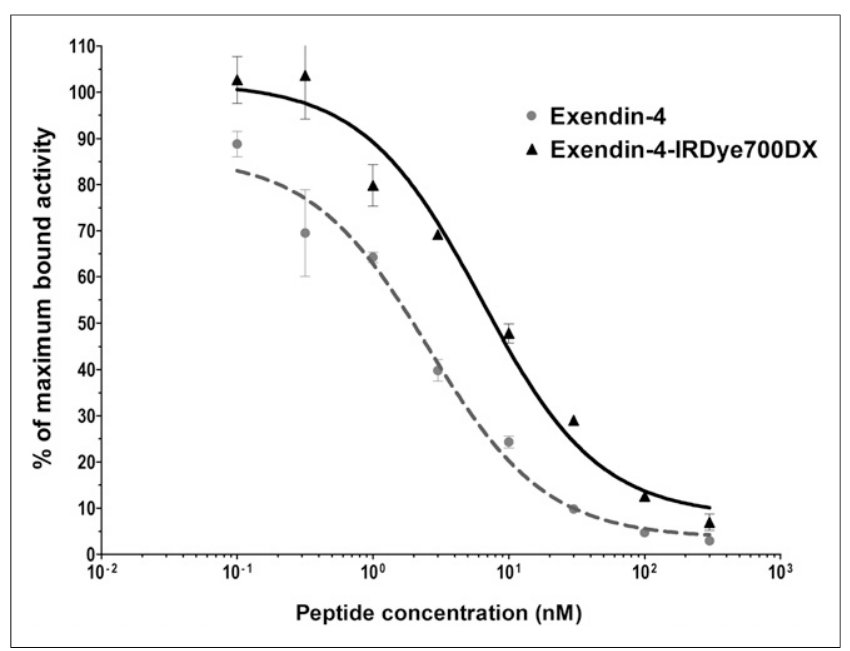

FIGURE 1. Competition binding assay (half-maximal inhibitory concentration) using CHL-GLP-1 cells of unlabeled exendin-4 and exendin4-IRDye700DX. ${ }^{111}$ In-DTPA-exendin-4 was used as tracer.

(excitation wavelength, $620 \mathrm{~nm}$; emission wavelength, $700 \mathrm{~nm}$ ). Standard curves and tracer uptake were calculated using Microsoft Office Excel 2007.

\section{rtPDT In Vivo: Immunohistochemistry}

Female BALB/c nude mice with subcutaneous GLP-1R-positive xenografts ( 8 mice per group) were injected intravenously with $30 \mu \mathrm{g}$ of exendin-4-IRDye700DX in $200 \mu \mathrm{L}$ of PBS with $0.5 \%$ BSA or in 200 $\mu \mathrm{L}$ of PBS with $0.5 \%$ BSA only and, after $4 \mathrm{~h}$, exposed to $100 \mathrm{~J} /$ $\mathrm{cm}^{2}$ NIR LED light. One group was treated only with exendin-4IRDye700DX without NIR light exposure. At 2 or $24 \mathrm{~h}$ after NIR light exposure, the mice were killed by $\mathrm{CO}_{2}$ asphyxiation. Tumors were harvested, fixated in $4 \%$ buffered formalin, embedded in paraffin, and sectioned at a $4-\mu \mathrm{m}$ thickness. Slices were deparaffinized with xylene and rehydrated in ethanol. Antigen was retrieved with $10 \mathrm{mM}$ citrate, pH 6.0, in a PT-Module (Thermo Fisher Scientific) $\left(10 \mathrm{~min}, 96^{\circ} \mathrm{C}\right)$. Endogenous peroxidase activity was quenched with $3 \% \mathrm{H}_{2} \mathrm{O}_{2}$ for $10 \mathrm{~min}$. Slices were incubated with $20 \%$ normal goat serum for
$30 \mathrm{~min}$ and subsequently with rabbit-anticleaved caspase-3 (1:4,000 in PBS $+1 \%$ BSA, ASP175; Cell Signaling Technology) in a humidified chamber at $4^{\circ} \mathrm{C}$ overnight in the dark. Slides were then washed 3 times with $10 \mathrm{mM}$ PBS and incubated with goat-antirabbit-biotin (1:200 in PBS $+1 \%$ BSA; Vector Laboratories) for $30 \mathrm{~min}$ at room temperature. After being washed with PBS, slides were incubated with Vectastain Elite $\mathrm{ABC}$ kit (Vector Laboratories) for $30 \mathrm{~min}$ at room temperature. The bound antibodies were visualized using diaminobenzene (Bright-DAB, catalog no. BS04 Immunologic; VWR). Slides were counterstained with 3-times-diluted hematoxylin (Klinipath) for $5 \mathrm{~s}$ and mounted with a cover slip (Permount; Fisher Scientific).

The immunohistochemical staining was independently analyzed by 2 masked observers. Scores were allocated to each slide following an ordinal 6-point scale ranging from 0 to 5 ( 0 , no staining; 1 , very weak staining; 2, weak staining; 3 , intermediate staining; 4, intense staining; 5 , very intense staining). The scores of the 2 observers were averaged.

\section{rtPDT In Vivo: Survival}

Female BALC/c nude mice with CHL-GLP-1R xenografts were randomized into 2 groups of 8 animals based on tumor size. When tumors were at least $30 \mathrm{~mm}^{3}$, the mice were injected intravenously with $30 \mu \mathrm{g}$ of exendin-4-IRDye700DX in $200 \mu \mathrm{L}$ of PBS with $0.5 \%$ BSA or PBS with $0.5 \%$ BSA only. After $4 \mathrm{~h}$, the mice were exposed to $150 \mathrm{~J} / \mathrm{cm}^{2}$ of NIR LED light under inhalation anesthesia $(2.5 \%$ isoflurane mixed with $\left.100 \% \mathrm{O}_{2}(1 \mathrm{~L} / \mathrm{min})\right)$. The kidneys were protected from exposure by covering them with gauze and aluminum foil. Tumor diameters were measured by a masked observer 3 times per week in 3 dimensions using a caliper. The mice were euthanized by $\mathrm{CO}_{2}$ asphyxiation when tumor volume reached more than $1,000 \mathrm{~mm}^{3}$ (tumor volume was calculated by $1.25 \times \pi \times[([$ length + width + height $\left.] / 6)^{3}\right]$ ). Overall survival was defined as the day that tumors reached a size of $1,000 \mathrm{~mm}^{3}$.

\section{Statistics}

Statistical calculations were performed using Prism (version 5.03; GraphPad Software). Half-maximal inhibitory concentrations were calculated by fitting the data with nonlinear regression using a leastsquares fit with Prism. In vitro cell viability after various treatments, assessed by a CellTiter-Glo assay, were compared by 2-way ANOVA with post hoc Bonferroni tests. Tracer uptake in various tumors was compared between the different injected doses by 1-way ANOVA.

Survival curves were compared by the logrank (Mantel-Cox) test using Prism.

\section{Study Approval}

All animal experiments were approved by the institutional Animal Welfare Committee of the Radboud University Medical Centre and were conducted in accordance with the guidelines of the Revised Dutch Act on Animal Experimentation.

\section{RESULTS}

\section{Exendin-4-IRDye700DX Binds GLP-1R with High Affinity}

The half-maximal inhibitory concentrations of exendin-4 and exendin-4-IRDye700DX were $2.54 \mathrm{nM}$ (95\% confidence interval, 1.32-4.90) and $6.25 \mathrm{nM}(95 \%$ confidence interval, 3.07-12.74), respectively (Fig. 1). Although the binding affinity of the labeled peptide was significantly lower than that of the unlabeled peptide $(P<0.0001)$, it 


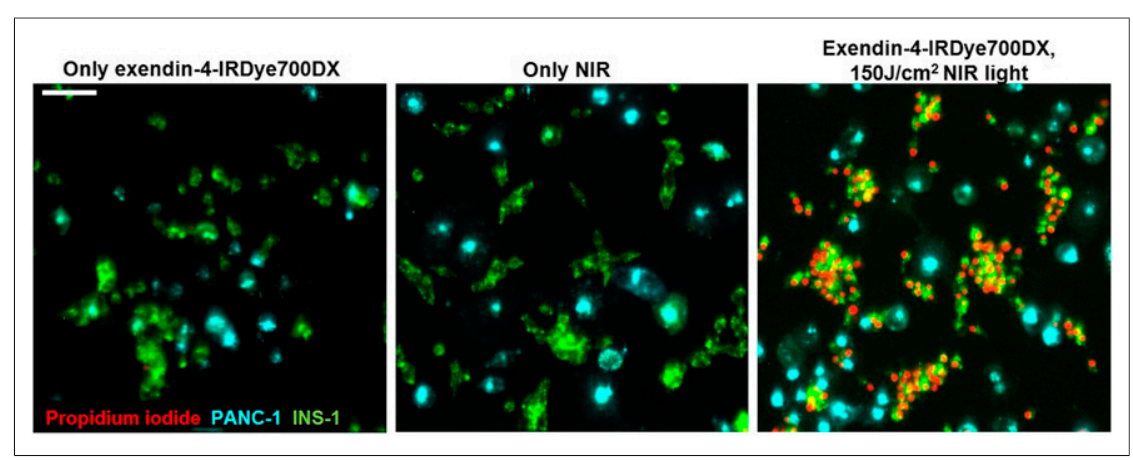

FIGURE 3. Fluorescence microscopy of INS-1 cells labeled with fluorescent dye DiO (green) and PANC-1 cells labeled with fluorescent dye DiD (cyan), cocultured and incubated with propidium iodide (red), after incubation of exendin-4-IRDye700DX or only binding buffer and with and without NIR irradiation with radiant exposure of $150 \mathrm{~J} / \mathrm{cm}^{2}$. Scale bar denotes $100 \mu \mathrm{m}$.

bound with a high affinity to the GLP-1R in the nanomolar range.

\section{In Vitro rtPDT with Exendin-4-IRDye700DX and NIR Light Causes Specific GLP-1R-Positive Cell Death}

rtPDT with exendin-4-IRDye700DX caused significant phototoxicity in cells with high GLP-1R expression (CHL-GLP-1R cells) and in the rat insulinoma cell line (INS-1 cells), with GLP$1 \mathrm{R}$ expression comparable to that in human insulinomas. The remaining cell viabilities were $2.3 \% \pm 0.8 \%$ and $2.7 \% \pm 0.3 \%$, respectively (Fig. 2). In PANC-1 cells, no cellular phototoxicity was observed under these conditions $(96.1 \% \pm 1.2 \%$ viable cells). Coincubation with an excess of unlabeled exendin- 4 abolished the phototoxic effect in CHL-GLP-1R cells and in INS-1 cells (99.3 \pm 1.3 and $98.4 \% \pm 2.1 \%$ cell viability, respectively). NIR light irradiation alone did not cause cellular phototoxicity in any of the cell types $(106.6 \% \pm 1.2 \%, 102.5 \% \pm 5.9 \%$, and $102.0 \% \pm 1.8 \%$ viable cells in CHL-GLP-1R, INS-1, and PANC-1 cells, respectively). No dark toxicity of the tracer was observed $(103.3 \% \pm 6.7 \%, 105.2 \% \pm$ $4.7 \%$, and $103.6 \% \pm 1.4 \%$ cell viability without irradiation in CHLGLP-1R, INS-1, and PANC-1 cells, respectively). Incubation of a coculture of INS-1 and PANC-1 cells with exendin-4-IRDye700DX followed by irradiation specifically caused cell death in INS-1 cells, as shown by colocalization of the red and green nuclei (Fig. 3). Absence of postinjection signal on rtPDT indicated that exendin-4IRDye700DX alone or NIR light alone did not cause cell death in either cell type.

\section{Improves Survival}

Analysis of the immunohistochemical staining revealed a low expression of cleaved caspase- 3 in the control groups. In both treatment groups, the expression of cleaved caspase- 3 was higher than in the control groups. Although the intensity of cleaved caspase- 3 staining was variable at $2 \mathrm{~h}$ after treatment, the intensity of the staining was high and uniform in the tumors $24 \mathrm{~h}$ after treatment, showing a significant induction of apoptosis in the tumors. The expression of cleaved caspase- 3 was slightly increased in the control group receiving only NIR light irradiation, showing that the light itself induces some cell death, most likely because of the heat produced by the LED light source (Fig. 5).

At the start of the survival experiment, the sizes of the subcutaneous GLP-1R tumors were very variable, although mean tumor sizes were similar between the groups $\left(161 \pm 205 \mathrm{~mm}^{3}\right.$ [range, 35-657 $\mathrm{mm}^{3}$ ] in the exendin-4-IRDye700DX group and $171 \pm 144 \mathrm{~mm}^{3}$ [range, $36-480 \mathrm{~mm}^{3}$ ] in the control group. On light exposure, tumor growth was slower in the group that received exendin-4-IRDye700DX, leading to a significantly longer median survival in this group than in the control group (36.5 vs. 22.5 d, respectively; $P<0.05$ ) (Fig. 6).

\section{DISCUSSION}

Treatment of hyperinsulinemic hypoglycemia is challenging. To address this issue, a strategy that specifically destroys GLP-1Rpositive cells with rtPDT was developed as an alternative treatment option for all forms of hyperinsulinemic hypoglycemia.

We showed the effectiveness of rtPDT with exendin-4-IRDye700DX in vitro and in vivo. The specific cytotoxic effect demonstrated that rtPDT with exendin-4IRDye700DX might enable destruction of GLP-1R-positive lesions without damaging the surrounding pancreatic tissue.

To our knowledge, this is the first evidence of the effectiveness of a peptide-based agent for rtPDT in vivo. In the current development of tracers for rtPDT, the most widely used carrier molecules are monoclonal antibodies and nanoparticles, because of their slow clearance from the circulation and high uptake in target organs. A single
FIGURE 4. Biodistribution of exendin-4-IRDye700DX (1, 3, and $10 \mu \mathrm{gg} ; 5$ mice per group) in tumors, spleen, pancreas, kidneys, and liver of female BALB/c nude mice $4 \mathrm{~h}$ after tracer injection. (A) Relative uptake expressed as percentage injected dose (\%ID) per gram of tissue. (B) Absolute uptake expressed as micrograms of exendin-4-IRDye700DX per gram of tissue.

\section{in GLP-1R-Positive Tumors
Relative uptake of exendin-4-IRDye700DX}

in subcutaneous GLP-1R tumors in mice was $3.9 \% \pm 1.9 \%$ injected dose/g for a 1 $3.3 \% \pm 0.6 \%$ for a $3-\mu \mathrm{g}$ tracer dose and $2.5 \% \pm 0.8 \%$ for a $10-\mu \mathrm{g}$ tracer dose $(P$ $=0.25$ ) (Fig. 4). As a result, the absolute injected tracer doses to $25.0 \mu \mathrm{g} / \mathrm{g}$ with a $10-\mu \mathrm{g}$ tracer injection. Uptake of exendin4-IRDye700 was highest in the kidneys,

In Vivo rtPDT Causes Cell Death in 


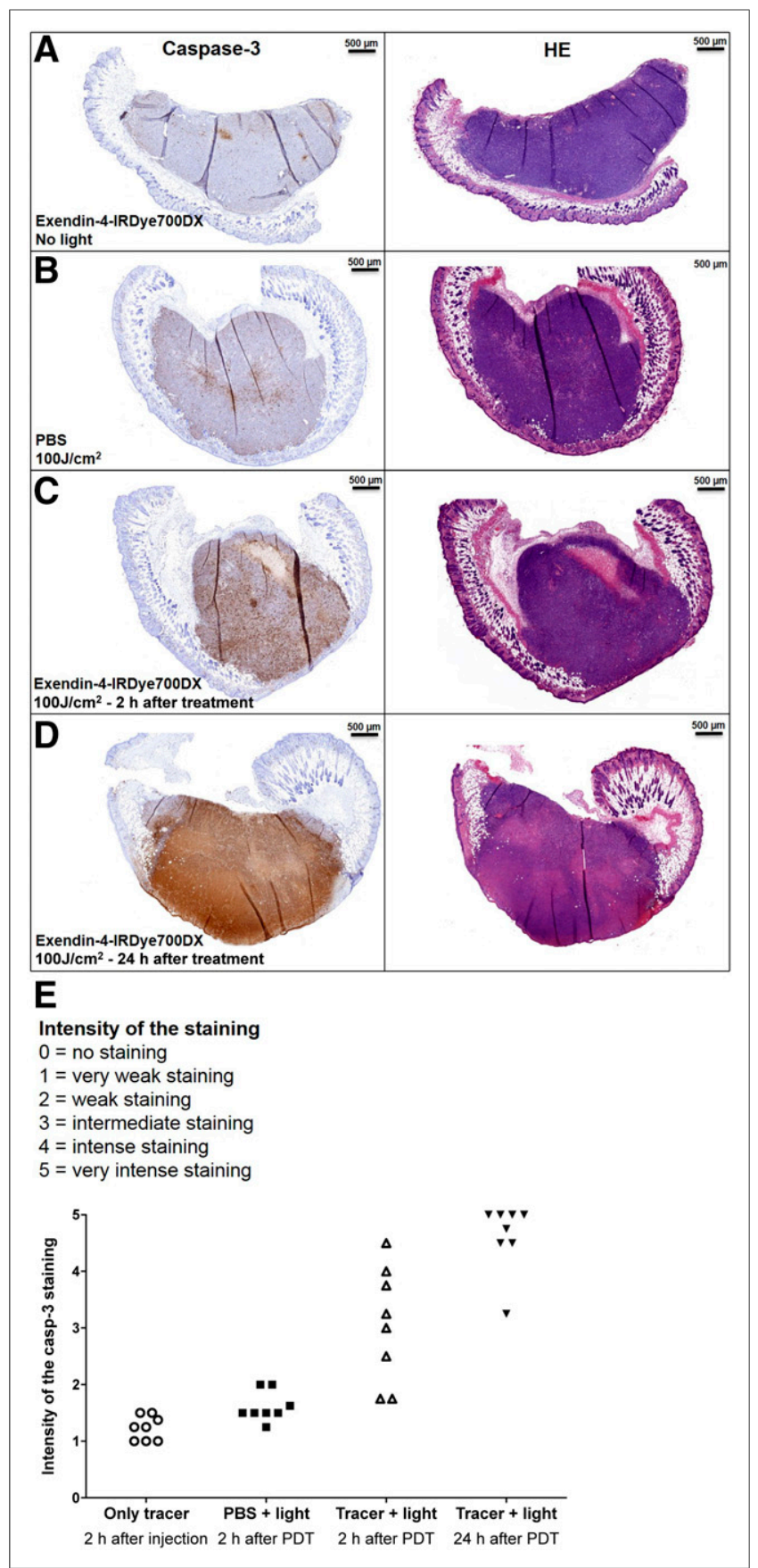

FIGURE 5. Representative examples of cleaved caspase-3 and hematoxylin and eosin (HE) staining of CHL-GLP-1R tumors. (A) Control tumors after intravenous administration of exendin-4-IRDye700DX. (B) Control tumors after only illumination. (C) Tumors after intravenous administration of exendin-4-IRDye700DX and illumination, dissected after 2 h. (D) Tumors after intravenous administration of exendin-4IRDye700DX and illumination dissected after $24 \mathrm{~h}$. (E) Intensity scores of capase-3 staining for tumor sections of all mice.

previous study examining rtPDT using various targeting peptides was limited to in vitro studies and showed no efficient cytotoxic effect (22).

We believe that rtPDT with exendin-4-IRDye700DX has the potential to be used as a minimally invasive technique to destroy insulin-producing cells with minimal morbidity. On delivery of the

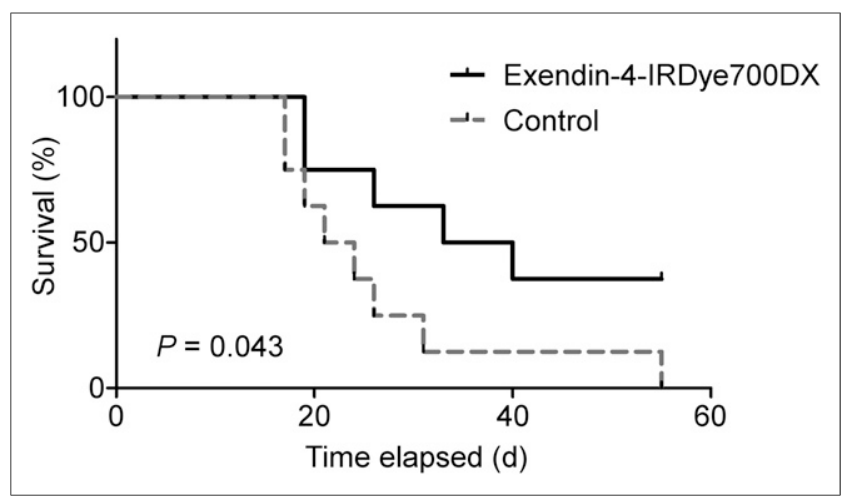

FIGURE 6. Kaplan-Meier plot of survival of BALB/c nude mice with GLP-1R-positive tumors after injection of $30 \mu \mathrm{g}$ of exendin-4IRDye700DX or PBS (control), followed by illumination with radiant exposure of $150 \mathrm{~J} / \mathrm{cm}^{2}$.

tracer, NIR light can be administered interstitially using diffuser fibers placed into the target tissue. Using this method of so-called interstitial PDT, it is feasible to deliver light to deeply seeded lesions or tissues. Successful results of interstitial PDT have been obtained in, for example, prostate cancer (23), head and neck cancer (24), and, importantly, pancreatic tumors (25). An optimal treatment result depends on optimization of the number of light sources and of their specific placement and power output (26-28). With percutaneous delivery, areas up to $23 \mathrm{~cm}^{2}$ can be treated (29), making the technique suitable for treatment of $\mathrm{CHI}$ and nesidioblastosis. Alternatively, the less invasive endoscopic delivery of a fiber can be applied for treatment of small lesions, since a single fiber can be applied using this technique $(30,31)$.

The data in this paper do not show $100 \%$ cell killing. Because these experiments were performed on an immunocompromised mouse model, they did not take into account the possible added effect on cell killing of the immune response elicited by PDT, as has been shown for other tumor types (32). Additionally, because of the minimal invasiveness of PDT, treatment can easily be repeated if hypoglycemia persists. Of interest, in a clinical situation, killing of enough cells to prevent overproduction of insulin will be sufficient, eliminating the need for $100 \%$ cell killing.

The receptor-targeted approach of PDT with exendin-4IRDye700DX enables specific killing of GLP-1R-expressing cells without damaging the surrounding tissue, and the focused irradiation of the tissue of interest avoids a risk of damaging the kidneys. Because treatment of nesidioblastosis and diffuse $\mathrm{CHI}$ will involve irradiation of a larger part of the pancreas, there is a risk that impaired glucose tolerance will develop. However, rtPDT has advantages over near-total pancreatectomy, since it avoids the risk of exocrine pancreatic insufficiency and is much less invasive. Also, localization and quantification of the insulin-overproducing cells based on preoperative PET images using radiolabeled exendin- 4 might be used for planning of the rtPDT to optimize the treatment and minimize side effects.

We believe that the data presented here, together with the advances in the technology of interstitial PDT, can provide a basis toward clinical translation of rtPDT using exendin-4-IRDye700DX. For this translation, verification of efficient targeting to human tissues, as well as the potential treatment efficacy by ex vivo analysis of human tissues, will be necessary before initiation of a first clinical trial. 


\section{CONCLUSION}

Here, we show the feasibility of rtPDT with exendin-4IRDye700DX, in the first demonstration of efficient PDT using small molecules in vivo. In the future, ablating insulin-producing cells using rtPDT with exendin-4-IRDye700DX might provide a new, minimally invasive treatment method for patients with hyperinsulinemic hypoglycemia. Since this treatment might be applied to a specific site of the pancreas in the case of insulinomas or focal $\mathrm{CHI}$ or to a larger pancreatic area in the case of nesidioblastosis or diffuse $\mathrm{CHI}$, it clearly has the potential to be effective to normalize blood glucose regulation in all forms of hyperinsulinemic hypoglycemia.

\section{DISCLOSURE}

This work was supported by BetaCure (FP7/2014-2018, grant agreement 602812). Martin Gotthardt is an inventor and holder of the patent "Invention Affecting GLP-1 and Exendin" (PhilipsUniversität Marburg, June 17, 2009). No other potential conflict of interest relevant to this article was reported.

\section{ACKNOWLEDGMENTS}

We thank Bianca Lemmers-van de Weem, Kitty LemmensHermans, Iris Lamers-Elemans, Karin de Haas-Cremers, and Mike Peters for their technical assistance in the animal experiments.

\section{KEY POINTS}

QUESTION: Does rtPDT with exendin-4-IRDye700DX enable effective and specific cell killing of GLP-1R-positive cells?

PERTINENT FINDINGS: rtPDT with exendin-4-IRDye700DX causes specific phototoxicity in GLP-1R-positive cells. The tracer accumulates in GLP-1R-positive tumors, and in vivo rtPDT causes cellular toxicity resulting in slower tumor growth.

IMPLICATIONS FOR PATIENT CARE: rTPDT with exendin-4IRDye700DX might provide a new, minimally invasive treatment method for patients with hyperinsulinemic hypoglycemia.

\section{REFERENCES}

1. Kinova MK. Diagnostics and treatment of insulinoma. Neoplasma. 2015;62:692-704.

2. Witteles RM, Straus IF, Sugg SL, Koka MR, Costa EA, Kaplan EL. Adult-onset nesidioblastosis causing hypoglycemia: an important clinical entity and continuing treatment dilemma. Arch Surg. 2001;136:656-663.

3. Senniappan S, Shanti B, James C, Hussain K. Hyperinsulinaemic hypoglycaemia: genetic mechanisms, diagnosis and management. J Inherit Metab Dis. 2012;35:589-601.

4. Lord K, Dzata E, Snider KE, Gallagher PR, De Leon DD. Clinical presentation and management of children with diffuse and focal hyperinsulinism: a review of 223 cases. J Clin Endocrinol Metab. 2013;98:E1786-E1789.

5. Iglesias P, Diez JJ. Management of endocrine disease: a clinical update on tumorinduced hypoglycemia. Eur J Endocrinol. 2014;170:R147-R157.

6. Okabayashi T, Shima Y, Sumiyoshi T, et al. Diagnosis and management of insulinoma. World J Gastroenterol. 2013;19:829-837.

7. Drymousis P, Raptis DA, Spalding D, et al. Laparoscopic versus open pancreas resection for pancreatic neuroendocrine tumours: a systematic review and metaanalysis. HPB (Oxford). 2014;16:397-406.

8. Fernández-Cruz L, Blanco L, Cosa R, Rendon H. Is laparoscopic resection adequate in patients with neuroendocrine pancreatic tumors? World J Surg. 2008;32:904-917.
9. Kowalewski AM, Szylberg L, Kasperska A, Marszalek A. The diagnosis and management of congenital and adult-onset hyperinsulinism (nesidioblastosis): literature review. Pol J Pathol. 2017;68:97-101.

10. Richards ML, Gauger PG, Thompson NW, Kloos RG, Giordano TJ. Pitfalls in the surgical treatment of insulinoma. Surgery. 2002;132:1040-1049.

11. Dolmans DE, Fukumura D, Jain RK. Photodynamic therapy for cancer. Nat Rev Cancer. 2003;3:380-387.

12. Mitsunaga M, Ogawa M, Kosaka N, Rosenblum LT, Choyke PL, Kobayashi H. Cancer cell-selective in vivo near infrared photoimmunotherapy targeting specific membrane molecules. Nat Med. 2011;17:1685-1691.

13. Reubi JC, Waser B. Concomitant expression of several peptide receptors in neuroendocrine tumours: molecular basis for in vivo multireceptor tumour targeting. Eur J Nucl Med Mol Imaging. 2003;30:781-793.

14. Christ E, Wild D, Ederer S, et al. Glucagon-like peptide-1 receptor imaging for the localisation of insulinomas: a prospective multicentre imaging study. Lancet Diabetes Endocrinol. 2013;1:115-122.

15. Christ E, Wild D, Forrer F, et al. Glucagon-like peptide-1 receptor imaging for localization of insulinomas. J Clin Endocrinol Metab. 2009;94:4398-4405.

16. Wild D, Macke H, Christ E, Gloor B, Reubi JC. Glucagon-like peptide 1-receptor scans to localize occult insulinomas. N Engl J Med. 2008;359:766-768.

17. Detty MR, Gibson SL, Wagner SJ. Current clinical and preclinical photosensitizers for use in photodynamic therapy. J Med Chem. 2004;47:3897-3915.

18. van Eyll B, Lankat-Buttgereit B, Bode HP, Goke R, Goke B. Signal transduction of the GLP-1-receptor cloned from a human insulinoma. FEBS Lett. 1994;348:7-13.

19. Brom M, Joosten L, Oyen WJ, Gotthardt M, Boerman OC. Radiolabelled GLP-1 analogues for in vivo targeting of insulinomas. Contrast Media Mol Imaging. 2012;7:160-166.

20. Jodal A, Lankat-Buttgereit B, Brom M, Schibli R, Behe M. A comparison of three ${ }^{67 / 68} \mathrm{Ga}$-labelled exendin-4 derivatives for beta-cell imaging on the GLP-1 receptor: the influence of the conjugation site of NODAGA as chelator. EJNMMI Res. 2014;4:31.

21. de Boer E, Warram JM, Hartmans E, et al. A standardized light-emitting diode device for photoimmunotherapy. J Nucl Med. 2014;55:1893-1898.

22. You H, Yoon HE, Jeong PH, Ko H, Yoon JH, Kim YC. Pheophorbide- $\alpha$ conjugates with cancer-targeting moieties for targeted photodynamic cancer therapy. Bioorg Med Chem. 2015;23:1453-1462.

23. Trachtenberg J, Weersink RA, Davidson SR, et al. Vascular-targeted photodynamic therapy (padoporfin, WST09) for recurrent prostate cancer after failure of external beam radiotherapy: a study of escalating light doses. BJU Int. 2008;102:556-562.

24. Lou PJ, Jager HR, Jones L, Theodossy T, Bown SG, Hopper C. Interstitial photodynamic therapy as salvage treatment for recurrent head and neck cancer. Br J Cancer. 2004;91:441-446.

25. Bown SG, Rogowska AZ, Whitelaw DE, et al. Photodynamic therapy for cancer of the pancreas. Gut. 2002;50:549-557.

26. Kim MM, Darafsheh A. Light sources and dosimetry techniques for photodynamic therapy. Photochem Photobiol. 2020;96:280-294.

27. van Doeveren TEM, Bouwmans R, Wassenaar NPM, et al. On the development of a light dosimetry planning tool for photodynamic therapy in arbitrary shaped cavities: initial results. Photochem Photobiol. 2020;96:405-416.

28. Dupont C, Baert G, Mordon S, Vermandel M. Parallelized Monte-Carlo dosimetry using graphics processing units to model cylindrical diffusers used in photodynamic therapy: from implementation to validation. Photodiagnosis Photodyn Ther. 2019;26:351-360.

29. Huggett MT, Jermyn M, Gillams A, et al. Phase I/II study of verteporfin photodynamic therapy in locally advanced pancreatic cancer. Br J Cancer. 2014;110: 1698-1704.

30. DeWitt JM, Sandrasegaran K, O'Neil B, et al. Phase 1 study of EUS-guided photodynamic therapy for locally advanced pancreatic cancer. Gastrointest Endosc. 2019;89:390-398.

31. Choi JH, Oh D, Lee JH, et al. Initial human experience of endoscopic ultrasoundguided photodynamic therapy with a novel photosensitizer and a flexible laserlight catheter. Endoscopy. 2015;47:1035-1038.

32. Beltrán Hernández I, Yu Y, Ossendorp F, Korbelik M, Oliveira S. Preclinical and clinical evidence of immune responses triggered in oncologic photodynamic therapy: clinical recommendations. J Clin Med. 2020;9:333. 